\title{
ESTALOS NAS VIGAS: LITERATURA E DESENHOS DE ALFRED KUBIN
}

\author{
Maria Aparecida Barbosa ${ }^{1}$
}

Resumo: $\mathrm{O}$ presente artigo compila as anotações de um estudo literário sobre a obra de Albert Kubin (Leitmeritz, 1877-Zwickledt, 1959), ilustrador e escritor austríaco. Kubin pertence à tradição de Bosch e de Breughel; ele igualmente representou os pesadelos, os medos, a loucura na obra artística, em seu caso tanto pictorica como literariamente. Kandinsky e Jünger destacam o papel e o valor do trabalho de Kubin dentre as artes expressionistas pela maneira como o artista percebia a condição de sua época em sintomas da decadência - nos estalos das vigas e a expressava em desenhos visionários, terríveis e proféticos. $\mathrm{O}$ objetivo deste artigo é fazer confluir os depoimentos desses contemporâneos, a análise das pinturas, ilustrações e écfrases literárias de Kubin, a sua correspondência epistolar com o ilustrador brasileiro Oswaldo Göeldi (1895-1961), bem como finalmente a leitura de seus textos autobiográficos. $\mathrm{O}$ acervo dessas informações há de auxiliar nas decisões tradutológicas de registros e vernáculos do romance ilustrado Die andere Seite/O Outro Lado, de 1909.

Palavras-chave: Alfred Kubin; expressionismo; Die andere Seite/O Outro Lado; livro ilustrado.

Zusammenfassung: Dieser Beitrag stellt die Aufzeichnungen einer literaturwissenschaftlichen Forschung über Albert Kubin vor (Leitmeritz, 1877-Zwickledt, 1959), österreichischer Illustrator und Schriftsteller. Kubin steht in der Tradition eines Bosch, eines Breughel; er stellt ganz ähnlich die Alpträume, die Ängste, den Wahnsinn in seinen Bildern dar, in seinem Fall eben sowohl bildhaft als auch literarisch. Kandinsky und Jünger heben die Rolle und den Wert von Kubins Werken innerhalb der expressionistischen Kunst hervor, und zwar wegen der Art und Weise, in der der Künstler die Verhältnisse der Epoche, die Symptome des Verfalls, eben die Risse im Gebälk wahrnahm und das alles in visionären, schrecklichen und prophetischen Zeichnungen realisiert. Das Ziel des Beitrags ist es, die Zeugnisse dieser Zeitgenossen, die Analyse von Kubins

\footnotetext{
${ }^{1}$ Profa. Associada UFSC - aparecidabarbosaheidermann@gmail.com
} 
36 | Maria Aparecida Barbosa

Gemälden, Zeichnungen und literarischen Beschreibungen sowie seiner Korrespondenz mit dem brasilianischen Illustrator Oswaldo Göeldi (1895-1961) und schliesslich die Lektüre seiner autobiographischen Texte zusammenzuführen. Diese Informationen sollen die Übersetzungsentscheidungen bei der Übertrragung des illustrierten Romans: Die andere Seite / O Outro Lado, 1909, nachvollziehbar machen. Schlüsselwörter: Alfred Kubin; Expressionismus; Die andere Seite; illustriertes Buch.

Este artigo reporta algumas anotações da minha pesquisa sobre a obra em matéria de literatura e arte visual de Alfred Kubin (Leitmeritz, 1877-Zwickledt, na Áustria, 1959), além de trazer no final a tradução de um trecho do romance de sua autoria, Die andere Seite/O Outro Lado. Kubin é conhecido pelas ilustrações de obras literárias de Edgar A. Poe, Fiodor Dostoievski, E. T. A. Hoffmann, August Strindberg, Jean Paul, Voltaire, Honoré de Balzac, Hugo von Hofmannsthal, Gerhart Hauptmann, Annette von Droste-Hülshoff, Franz Werfel, Gustav Meyrink, Paul Scheerbart, bem como pelos desenhos para uma edição do Livro de Daniel do Velho Testamento. Sua forma de expressão foram a pintura e o desenho, embora esses trabalhos estejam sempre conjugados com o texto escrito.

Os biógrafos afirmam que o romance, seu único texto considerável, teria sido concebido num interstício de crise com a pintura. Em 23 de dezembro de 1908, referindo-se às 52 ilustrações que originalmente integram a edição do romance, Kubin confessou: Esses desenhos constituem o melhor que eu já fiz até agora, o texto elucidativo é apenas moldura. Eu, pessoalmente, não quero estrear como escritor. (METZLER 1986: p. 391). Embora o autor prezasse as ilustrações e as considerasse o cerne do livro, enquanto o texto literário, a seu ver, não passava de acessório, para enorme prejuízo da leitura a edição Rowohlt Taschenbuch de 2001 priorizou o texto literário e renunciou ao conjunto das ilustrações, mantendo somente uma delas na arte da capa.

Kandinsky destaca seu espírito lúcido, sensível para perceber e apontar à ruína como um arauto: Entre estes visionários da decadência está, em primeiro lugar, Alfred Kubin. Com força irresistivel nos arrasta à atmosfera aterradora do vazio implacável. Esta força brota dos desenhos de Kubin, mas também de seu romance Die andere Seite. E Ernst Jünger, no ensaio "Os Demônios da Poeira, um estudo sobre a obra de Alfred Kubin", texto 
publicado originalmente no Jornal Hamburger Nachrichten em 1931, considera Kubin referência imprescindível na pesquisa sobre gêneros artísticos Fantástico, Realismo Mágico etc., devido à ousada maneira como sintetiza a vanguarda expressionista. Sobre sua pintura ele escreve:

A vida das pessoas é vista em momentos oníricos; ela é de uma atividade demoníaca ou de uma inércia apática, vegetal. Surgem figuras, cuja aparição surpreende pela sua maneira fantasmagórica, e outras, que nem supõem estar sendo espreitadas em seus movimentos mais secretos. Torna-se viva aqui a curiosidade aflita dos contos de fadas, como a que acomete crianças ante baús proibidos. Uma espécie de atividade, cujo sentido ou falta de sentido fica vedado ao próprio ator, é vista como que através de rachaduras na parede, buracos de fechadura ou telescópios antiquados. (JÜNGER: s. data: p. 496)

Os depoimentos desses contemporâneos atribuem a Kubin, portanto, papel preponderante na pintura expressionista. É preciso lembrar que o contexto quando da escritura do romance é o período anterior à Primeira Guerra. O tom apocalíptico de sua escritura faz clara alusão a um futuro maniqueísta. Seus desenhos são legados como se fossem claves que revelam a crônica da época registrada nos estalos das vigas, nas teias de aranha e nas rachaduras em paredes, como acentua Jünger (Idem: 498).

A narrativa do romance $O$ Outro Lado apresenta a sensação de isolamento e desespero do indivíduo no espaço. Está constituído por três partes: "Der Ruf" (O Chamado), "Perle" (Pérola), "Der Untergang des Traumreichs" (O Declínio do Reino os Sonhos), e "Schluss" (Epílogo). Tanto no trecho inicial de "O Chamado" como na Segunda Parte, o narrador tenta explicar a origem de suas fantasias e, para constituir o parâmetro do que convencionou chamar "real", ele recorre ao argumento documental: se propõe a relatar no livro suas vivências ou os depoimentos de outras pessoas do Reino dos Sonhos.

Convidado (na verdade, seduzido através de uma bela quantia de dinheiro) pelo ex-camarada de ginásio Patera, uma enigmática figura, da qual muito se conta, mas que, ao que tudo indica, prefere manter-se incógnita e misteriosa, o narrador parte com a mulher com a intenção de participar do ambicioso projeto de um novo mundo, nos confins asiáticos. A expectativa de encontrar um lugar onde estivessem em vigor 


\section{8 | Maria Aparecida Barbosa}

instituições justas se frustra terrivelmente, quando ele se depara com um reino obscuro e decadente. Em seu registro, bem ao contrário de uma sociedade de espaço utópico, conforme o Estado do Sol (publicado em 1623, por Tommaso Campanella), a Utopia (1517, por Thomas Morus), ou a Nova Atlântida (1638, por Francis Bacon), o narrador expressa o malogro, uma experiência fracassada de sociedade.

Dispersos por todo o romance, estão descrições, através das quais se evidencia o domínio da perspectiva, da profundidade de campo, dos traços, das cores: afinal se trata da literatura de um pintor, cujo protagonista narrador em primeira pessoa é um ilustrador. Na descrição da capital Pérola, citada abaixo, é como se o texto literário fosse uma écfrase do quadro "Ahnung" pintado por Kubin em 1906. Observo a tentativa de ampliar o campo semântico das palavras, atribuindo-lhes sensações originárias da visão, que se persegue igualmente na tradução.

(...) mas o céu, que se via ali, era eternamente nublado; o sol nunca brilhava, a lua ou as estrelas nunca eram visíveis à noite. As nuvens estavam constantemente baixas, tocando a terra. Víamos os escuros cúmulos nas tempestades, mas nunca o firmamento azul.

Um erudito professor, sobre o qual voltarei a falar, associava a persistente nebulosidade pardacenta aos vastos pântanos e florestas. Eu, sinceramente, não vi o sol uma única vez durante esses anos. No começo, sofri muito por isso, e o mesmo se passava com todo recém-chegado. Às vezes, porém, as formações de nuvens possuíam uma luminosidade surpreendente, inclusive alguns raios de luz indireta vinham incidir sobre nossa cidade, sobretudo no final da minha estada em Pérola. Mas nunca chegava a ser um triunfante céu aberto - nunca.

Sob essas condições é fácil imaginar o aspecto da terra com seus campos e florestas. Em lugar algum se via um verde forte. As plantas, matos, arbustos e árvores eram encobertos por um verde-oliva embotado. $O$ que na nossa terra se destacava em brilhantes colorações, aqui era fosco, apagado.

$\mathrm{Na}$ maioria das paisagens, o azul do céu e o amarelo da terra dominavam, enquanto as outras tonalidades surgiam apenas esparsas. Mas aqui o cinza e o marrom predominavam. O melhor, o colorido faltava. Harmônica 
Estalos nas vigas - literatura e desenhos de Alfred Kubin | 39

era a visão do Reino dos Sonhos, isso é preciso admitir. (KUBIN 2001: p. 51-52)

As palavras colorem o céu, e o universo de cores restringe-se aos sobre-tons dentro da gama cinzenta das nuvens, apesar de todas as variações. A longa digressão a respeito da monotonia da paisagem vai se estender ao tempo e às estações do ano. A princípio uma referência literal, essas palavras terão seu sentido ampliado metaforicamente e conferirão um atributo plástico ao tédio das ruas da cidade, da vida dos seus habitantes. Após pincelar a paisagem, o foco se aproxima da urbis:

Uma imponente cordilheira delimita o reino ao norte. Seu cume estava constantemente coberto pela região de névoa. A passagem para a planície é íngreme e abrupta, e ali está a origem de uma poderosa nascente de água: a do Negro. Esse rio desaba em violentas cascatas montanha abaixo e se alarga na saída de uma colina estreita. Então, suas águas fluem a partir dali numa coloração escura, quase um rio de nanquim que traça um arco. Justamente nesse local foi fundada a capital do Reino dos Sonhos. Tristemente sombria Pérola se ergue do pobre solo numa uniformidade incolor. (KUBIN 2001: p. 52-53)

É alternando, pois, na escritura profundidade de campo e ação pretensamente documental com a narrativa em primeira pessoa, que se constrói o contraste e o paradoxo, característicos dessa literatura. Meyrink e Franz Kafka empregaram estratagemas análogos.

Aliás, a experiência da personagem do romance de Kubin ressurge no conflito da figura $\mathrm{K}$. com seus antagonistas dentro da narrativa do romance Der Prozess, que Kafka escreveu entre 1914 e 1915, mas só viria a ser publicado em 1925. O ilustrador, protagonista do romance de Kubin, procura em vão uma maneira de ser recebido pelo seu anfitrião, o senhor absoluto do Reino dos Sonhos, enquanto K. esperava ser atendido pela autoridade, por alguém que pudesse lhe fazer justiça.

A afinidade espiritual de Kubin com outros artistas contemporâneos seus é comumente observada por biógrafos e críticos. $\mathrm{O}$ acervo do Museu Casa de Kubin em Zwickledt (Kubin-Haus), na Áustria, possui cartas, nas quais, entre outros o pintor Lyonel Feininger (Nova 
Iorque, 1871-1956) exprime a sedução que exerciam sobre ele os desenhos do Kubin.

Graças à potência que aterrorizava e ao mesmo tempo revelava rumos a vários artistas, o conjunto de sua obra motivou diversas pesquisas. Uma delas contemplou o diálogo entre Kubin e o artista brasileiro Oswaldo Goeldi (Rio de Janeiro, 1895-1961), conhecido ilustrador de obras literárias brasileiras canônicas, como as edições originais de Canaã, de Graça Aranha, Cobra Norato, de Raul Bopp, ou a edição mais conhecida do romance Mar Morto, de Jorge Amado, que a Martins Fontes publicou em 1967. Em Oswaldo Goeldi - uma autobiografia se ressalta no estilo de Goeldi justamente a relação que também marcou o trabalho de Kubin: a imagem submissa ao texto como ilustração ou como uma tradução espontânea e autônoma.

O questionamento gráfico que aproximava os dois artistas plásticos pode ser observado também na literatura do romance $\mathrm{O}$ Outro Lado: o próprio texto verbal possui uma espécie de faculdade criadora de imagens de linguagem visual complementares às ilustrações que o autor preparou para compor a obra.

O livro sobre Goeldi reserva extensa exposição sobre a correspondência entre ambos os artistas, cujos trechos abaixo ilustram as demonstrações do vínculo espiritual que marcou sua sintonia profissional durante alguns anos. Conforme se depreende da evolução, da transformação das gravuras e dos desenhos, Goeldi acabou encontrando um próprio estilo, mais vivo e bem menos sombrio que o de Kubin.

Rio de Janeiro, 4/8/1926.

Caro Sr. Kubin,

Queira ter a bondade de olhar meus desenhos. Quem sabe o senhor possa recomendar-me à Piper Editora ou a outra grande editora artística? O desenho vem a ser uma função orgânica do meu eu, sem o qual o meu equilíbrio sofre. Talvez, se eu fosse mais conhecido, poderia dedicar-me totalmente ao desenho e perder algumas inibições que ainda sinto de vez em quando. Nota-se logo, sem dúvida, a forte influência que o senhor exerce sobre mim. O exemplo que senti na sua força artística levou-me ao bom caminho. Quero dizer-lhe da minha gratidão: o senhor abriu muitos caminhos novos à jovem geração de gráficos. Num momento crítico da minha vida, foi o senhor quem me deu 
Estalos nas vigas - literatura e desenhos de Alfred Kubin | 41 força; considero isto uma grande sorte e espero poder procurá-lo pessoalmente algum dia. Por favor, escreva-me dizendo o que acha destes trabalhos.

Oswaldo Goeldi.

Rio de Janeiro, 15/12/1950.

Caro Sr. Kubin,

(...) o livro de H. Esswein, Alfred Kubin, um Ensaio sobre o Artista e sua Obra foi o primeiro que me chamou a atenção e manifestou sua personalidade, tendo em efeito decisivo para mim - em 1917, em Berna. Sim, aos poucos avancei na idade - 56 anos. Dentro das minhas possibilidades, me esforcei honestamente - sempre com fidelidade para comigo mesmo e minha admiração inalterável pelo senhor. Com pouquíssimos materiais, pena e nanquim, o senhor refletiu o seu riquíssimo mundo interior de mil modos, e daí se conhece o mestre. Acho que foi a paixão, a imaginação ardente das suas criações - um verdadeiro visionário. Com o avanço da idade, admiro o eterno Kubin, que nunca fraquejou e permaneceu sempre jovem, que valor positivo! Poucos, sim, muito poucos do nosso tempo têm esta virtude "única" e maravilhosa do trabalho artístico. No meu completo isolamento, o seu exemplo sempre foi suficiente para mim.

Oswaldo Goeldi.

(RIBEIRO 1995: p. 176-177)

O diálogo entre Kubin e Goeldi incluía discussões técnicas sobre suas formas de trabalho e experimentos com novos materiais. As cartas constituíram um rico intercâmbio de informações e selaram durante 26 anos, no período que vai de 1926 a 1952, a afinidade plena de admiração e respeito mútuo entre os dois ilustradores. Essa amizade foi fundamental para associar o nome de Kubin ao Brasil, país onde ele, na III Bienal de Artes de São Paulo de 1955, foi premiado pela retrospectiva especial de seu trabalho.

Além do romance Die andere Seite, Kubin publicou os seguintes textos literários:

- $\quad$ as novelas reunidas num livreto chamado Der Guckkasten (Caixa de curiosidades), em 1925, (que C. David em sua tradução francesa 


\section{2 | Maria Aparecida Barbosa}

editada pela Allia denominou magnificamente Le Cabinet de curiosités et autres textes);

- juntando a esses mesmos textos informações sobre materiais e técnicas artísticas que empregava no trabalho de pintura, surge mais tarde Aus meiner Werkstatt (Do meu Ateliê).

- Dämonen und Nachtgesichte (Demônios e Rostos Noturnos) é publicado em Berlim, em 1926, com 130 reproduções de obras de diversas fases de criação, sendo que o prefácio contém comentários autobiográficos;

- uma coletânea de textos esparsos, Vom Schreibtisch eines Zeichners (Da Escrivaninha de um Desenhista), em 1939;

- $\quad$ postumamente, em 1970, foi publicado o livreto Aus meinem Leben (Minha Vida).

Apresento a seguir um trecho de minha tradução de Die andere Seite, publicado originalmente em München, pela Editora Georg Müller, no ano de 1909. Para efeito de minhas leituras tenho empregado a edição Editora Rowohlt, de 2001.

\section{O Outro Lado}

Primeira Parte: O Chamado

A Visita

Entre meus conhecidos do tempo de jovem, havia um sujeito singular cuja história vale a pena ser contada. Eu fiz o possível para descrever pelo menos uma parte dos estranhos fatos relacionados com o nome de Claus Patera.

Durante a narrativa, aconteceu-me algo inusitado: à medida que eu ia anotando muito compenetrado minhas próprias experiências, escapava-me sem que eu percebesse a descrição de situações que não presenciara e sobre as quais não poderia ter sido informado por outrem. Acabei contando, portanto, os fenômenos extraordinários que a proximidade de Patera gerou numa coletividade inteira. Precisei atribuir essas influências à minha misteriosa faculdade de clarividência. Quem desejar uma explicação, que se volte às pesquisas de espirituosos cientistas da alma e afins.

Eu conheci Patera há sessenta anos, em Salzburg, quando nós, ambos, entramos no ginásio local. Naquele tempo ele era um sujeito pequeno, porém de ombros largos e, no máximo, chamaria a atenção a 
sua basta cabeleira cacheada de corte antiquado. Meu Deus, nós éramos uns rapazes selvagens, malcriados e fazíamos pouco caso das formalidades. Apesar disso, como um homem idoso, preciso admitir ter guardado perfeitamente na memória os olhos muito grandes, levemente pronunciados, de cor cinza-clara. Mas, quem naquela época pensava em futuro?

Três anos depois eu troquei o ginásio por outra instituição de ensino, os contatos com meu ex-camarada foram se tornando mais esparsos, até que no final das contas, mudei de Salzburg para outra cidade e perdi de vista durante vários anos tudo o que me era familiar. O tempo foi passando e minha juventude foi se esvaindo, eu já vivera muitos momentos intensos e era um homem na faixa dos trinta anos, casado e pelejando para sobreviver como desenhista e ilustrador. Então, isso foi em Munique, onde nós morávamos, alguém me anunciou, numa nublada tarde de novembro, a visita de um desconhecido.

\section{- Entre!}

$\mathrm{O}$ visitante era - tanto quanto pude distinguir à meia-luz - um homem de aparência comum, que foi logo se apresentando:

- Franz Gautsch: seria possível conversarmos por uma meia hora?

Assenti, ofereci-lhe uma cadeira e pedi que trouxessem luz e chá.

- Como posso lhe ser útil?

Minha indiferença inicial transformou-se a princípio em curiosidade, depois em assombro, quando o estranho disse mais ou menos o seguinte:

- Eu lhe farei algumas propostas. Não falo por mim, mas em nome de um homem que o senhor talvez tenha esquecido, mas que ainda o tem gravado na memória. Esse homem possui riquezas de valor incalculável para os padrões europeus. Refiro-me a Claus Patera, seu antigo camarada de escola. Por favor, não me interrompa. Por um acaso singular, passou às mãos de Patera uma enorme fortuna, talvez a maior do mundo. Seu ex-colega pôs-se então a trabalhar para a concretização de uma idéia que pressupõe, de certa maneira, inesgotáveis bens materiais. Seu desejo era fundar um Reino dos Sonhos! O caso é complicado, eu serei breve.

- Inicialmente foi adquirida uma área apropriada de três mil quilômetros quadrados. Um terço do terreno é bastante acidentado, o restante perfazem uma planície e uma região de colinas. Grandes florestas, um lago e um rio partilham e vitalizam o pequeno reino. Foi construída uma cidade, vilarejos; a partir daí surgiu uma demanda, pois a 


\section{4 | Maria Aparecida Barbosa}

população inicial montava doze mil almas e agora o Reino dos Sonhos conta com sessenta e cinco mil habitantes.

O estranho sujeito fez uma breve pausa e bebeu um gole de chá. Eu estava bem quieto e falei ligeiramente embaraçado.

- Prossiga!

Então eu soube o seguinte:

- Patera nutre profunda repugnância contra todo e qualquer progresso. Digo e repito, contra todo e qualquer progresso, assim chamado o ramo científico. Nesse ponto, por favor, compreenda minhas palavras tão literalmente quanto possível, pois nelas está a idéia essencial do reino dos sonhos. O reino está delimitado dos arredores por um muro e protegido de quaisquer invasões por potentes equipamentos de segurança. Um único portão permite entrada e saída e facilita o rigoroso controle do acesso de pessoas e bens. O Reino dos Sonhos, asilo para pessoas insatisfeitas com a cultura moderna, está munido para atender todas as necessidades físicas dos habitantes. O senhor desse reino está longe de pretender criar uma utopia, um tipo de país do futuro. Só para mencionar de passagem, a carência material prolongada não existe ali. As metas mais nobres dessa sociedade estão menos voltadas para a manutenção de valores reais da população e de indivíduos isolados. Não, nada disso!... Mas eu o vejo sorrir incrédulo e, admito, é difícil para mim descrever com palavras aquilo que Patera de fato almeja com o Reino dos Sonhos.

- Antes de qualquer coisa, seria necessário notar que cada habitante do reino estava predestinado a sê-lo, por nascimento ou acaso posterior. É sabido que órgãos de sentido altamente apurados capacitam seus possuidores a conceber relações de um mundo peculiar, o que não é dado conhecer aos seres medianos, fora circunstâncias bem específicas. Veja bem, senhor, justamente o que não é dado conhecer perfaz a meta dos nossos esforços. Num sentido último e profundo é da base insondável do universo que o povo dos sonhos - assim se autodenominam - jamais se descuida.

- Vida normal e mundo onírico perfazem talvez uma contradição e essa diferença dificulte a compreensão. Perguntas, tais como: o que acontece no Reino dos Sonhos? Como se vive lá? Eu simplesmente não posso responder. Eu poderia fazê-lo um tanto superficialmente, contudo, faz parte da natureza intrínseca do nosso povo certa aspiração à profundidade. Tudo nos interessa o quanto possível pelo viés espiritual; o sofrimento e a alegria dos contemporâneos não são familiares ao sonhador. E, devido aos padrões de valoração tão diferentes das 
convenções o sonhador naturalmente precisa manter-se na ignorância desses sentimentos. Porém, um mínimo que seja, ao menos para efeito de analogia, o conceito de "disposição" deve ser esclarecido. Nosso povo vivencia somente estado de espírito, melhor dizendo, vive apenas em estados de espírito. Toda e qualquer estrutura social que ele molda através do trabalho, tão conjugado quando possível com os concidadãos segundo o arbítrio de cada um, resulta somente em matéria e há o cuidado para que essa não se esgote. Mas o sonhador não crê em nada além do sonho, do seu próprio sonho. E existe uma preocupação constante em nosso país no sentido de nutri-lo e fomentá-lo; perturbá-lo seria uma traição impensável.

- Isso explica o rigoroso critério de escolha das pessoas convidadas a participar da comunidade. Enfim e em suma, eu lhe digo o seguinte...

Gautsch apagou então o cigarro e olhou-me bem fundo nos olhos:

- Claus Patera, senhor absoluto do Reino dos Sonhos, encarregoume como agente a fim de convidá-lo a emigrar para esse país.

As últimas palavras, o meu visitante pronunciou um pouco mais alto e com muita formalidade. Em seguida o homem calou-se e eu, por minha vez, a princípio fiquei quieto, reação que meu leitor certamente compreenderá. Era quase natural que eu julgasse estar frente a frente com um louco. Foi sinceramente penoso disfarçar minha agitação. Como se estivesse brincando distraidamente, afastei o abajur do alcance do sujeito, ao mesmo tempo, escondi um compasso bem como um pequeno estilete, por causa das pontas, objetos perigosos.

A situação era, de fato, muito embaraçosa. No início daquela história de sonhos eu pensava que algum conhecido meu tentava me pegar com uma piada. Infelizmente, contudo, cada vez mais se desvanecia qualquer chispa de esperança nesse sentido, e há dez minutos eu vinha refletindo em desespero sobre as alternativas possíveis. Eu sabia que o melhor remédio quando se lida com loucos é entrar no jogo e concordar. Mesmo assim! Eu não sou nenhuma fortaleza, sou um sujeito retraído e fraco! No entanto, lá estava o solene Gautsch sentado na minha sala com seu aspecto de burocrata, lunetas e cavanhaque!

Mais ou menos esses pensamentos me ocorreram naquela contingência. Preciso acrescentar, além disso, que meu interlocutor aguardava uma resposta. $\mathrm{Na}$ pior das hipóteses, no caso de algum acesso de fúria eu poderia apagar a luz e sair furtiva e silenciosamente da sala.

- Claro, claro! Estou entusiasmado! Só preciso trocar umas palavras com minha mulher. Amanhã, Senhor Gautsch, eu lhe darei minha resposta. 
Eu falei assim num tom benevolente me levantando. Mas meu visitante permaneceu tranquilamente sentado e respondeu com secura:

- O senhor entendeu mal a proposição, o que é bastante compreensível. Mais provavelmente não está acreditando em mim, ou conforme indica sua irritação mal contida, está nutrindo uma suspeita contra minha pessoa. Dou-lhe minha palavra: estou bem de saúde, mais saudável do que qualquer um poderia estar. A comunicação que lhe fiz é séria; por estranha e esquisita que possa soar. Talvez vendo isso o senhor fique calmo!

Assim dizendo, mostrou-me um pequeno embrulho e o colocou a minha frente encima da mesa. Li meu endereço preciso, abri o selo e descobri um estojo elegante de cor cinza-esverdeado. Dentro dele encontrava-se uma pequena miniatura, o busto de um jovem. Cachos castanhos emolduravam um semblante de expressão antiga; os olhos, muito claros e pronunciados do relevo da escultura, fitavam-me atentamente: era sem dúvida nenhuma Claus Patera!... Nos últimos vinte anos durante os quais nós não nos vimos, eu quase nem pensava nesse camarada, que julgara completamente desaparecido. Ao contemplar a escultura fiel, o considerável interstício de tempo diminuiu subitamente em minha mente. Surgiram ante mim os corredores pintados de amarelo do Ginásio de Salzburg, vi novamente o bedel com seu digno papo escondido a duras penas pela barba rala. Novamente eu me vi em companhia dos outros rapazes, entre eles Claus Patera,

- De onde o senhor tirou esse busto? -, perguntei sem pensar, levado pela curiosidade.

- Estou lhe dizendo! -, respondeu meu interlocutor.

- Tenho a impressão de que seu receio desapareceu. -, prosseguiu ele com um sorriso bondoso e inocente.

- Mas isso é uma loucura, uma brincadeira, um embuste! -, saiu de dentro de mim junto com risadas.

O Senhor Gautsch me pareceu subitamente um homem normal e honrado. Lá estava ele concentrado em remexer o chá. Com certeza havia alguma piada atrás disso tudo, mais tarde eu haveria de esclarecer o mistério! Minha imaginação mais de uma vez me pregara uma peça! Como eu pude, por um instante sequer, considerar o sujeito maluco, só por causa de uma história dessas? Meu Deus do Céu, como a gente envelhece! Eu fiquei alegre e bem-humorado de repente.

- Na escultura, então, o senhor acredita? -, falou Gautsch.

- O seu amigo, nela representado, teve um destino bem original. Ele completou algumas poucas disciplinas de latim em Salzburg; com 
quatorze anos fugiu da casa da tia e circulou em companhia de ciganos pela Hungria e pelos Bálcãs. Dois anos mais tarde, chegou a Hamburg naquele tempo ele era domador de animais - e acabou trocando a profissão pela de marinheiro e alistou-se como marujo num pequeno cargueiro. Numa de suas viagens ele finalmente chegou à China. Ancorado ao cais do Cantão ao lado de vários outros navios, o cargueiro estava sendo abastecido com milho e arroz: uma medida de prevenção contra a carestia. Terminado o embarque, o navio foi obrigado a permanecer no porto, porque algumas mercadorias, como cabelo humano e um tipo de porcelana fina, não estavam prontas para a viagem.

- Patera aproveitava o tempo ocioso para passear pelo país. Foi nessa ocasião que ele salvou a vida de uma distinta chinesa, uma senhora idosa. Tendo escorregado na lama de uma região alagada, essa dama teria certamente se afogado e encontrado seu fim num daqueles canais fluviais do Cantão. Pessoas de tranças presentes no local - elas quase nunca nadam - estendiam as mãos e gritavam, mas não ousavam mergulhar nas águas turvas e marrons. Seu amigo, que é um mestre em mergulho, passava pelo local justamente naquele momento e não hesitou em pular na torrente. Após lutar contra a correnteza, conseguiu arrastar a inconsciente a terra. A mulher voltou a si. Tratava-se da esposa do homem mais rico do planeta; um alquebrado ancião, que logo em seguida chegou portado dentro de uma liteira. Muito agradecida, a velha senhora abraçou em silêncio o jovem salvador e o conduziu a uma grande casa de campo.

- $\mathrm{O}$ teor da conversa que teve lugar naquela ocasião permanece misterioso. O certo é que Hi-Yong não possuía descendência e decidiu adotar o pobre marujo como filho, e o manteve consigo em casa. Três anos mais tarde, dos quais só se tem notícia de que Patera viajou por regiões ignotas do continente asiático, ele estava em luto pela morte dos pais: Hi-Yong e sua mulher faleceram no mesmo dia. $\mathrm{O}$ herdeiro único e universal tomou posse de tesouros fabulosos e incalculáveis.

- E agora entra a história do Reino dos Sonhos. A idéia é original, se o senhor me permite vou passá-la a um amigo escritor que a transformará em bela literatura. -, intervim gracejando.

- $\mathrm{O}$ senhor aceita um cigarro? - , ofereci.

O visitante agradeceu, suspirou à maneira dos homens de negócio e observou num tom bastante calmo e claro:

Como eu já lhe disse, está patente para mim que o senhor me toma por um fanfarrão ou contador de lorotas. Devo lhe dizer, contudo, que não vim aqui a fim de convencê-lo sobre a veracidade do Reino dos 


\section{8 | Maria Aparecida Barbosa}

Sonhos, mas sim para convidá-lo em nome do meu comitente. Por ora, eu acredito ter cumprido minha missão. Se o senhor não confia no que eu expus, não há nada que eu possa fazer. Em todo o caso, peço-lhe uma confirmação do recebimento desse busto. É bem possível que eu venha a ter outras encomendas para lhe trazer em breve.

Gautsch levantou-se com uma leve inclinação. Para ser franco, o homem não parecia definitivamente ser um embusteiro. E o estojo estava em minhas mãos. Ao abri-lo novamente, percebi uma abertura de couro que não vira anteriormente, dentro da qual havia a frase escrita à tinta numa folha de papelão: se você quiser, venha!

Mais uma vez percorreu-me silenciosa e oniricamente uma lembrança do passado há muito esvaecido. Pretensiosa, confusa, desamparada e grande demais, assim era a letra do meu antigo camarada de escola; desesperada, denominou-a certa vez um professor. Notei que as quatro palavras do bilhete tinham sido inscritas com traços firmes, mas o autor era aparentemente o mesmo.

Um mal-estar estranho invadiu-me então; frio como gelo, o belo rosto me encarava. Dava para se perder nesses olhos nos quais havia algo de felino. Minha jovialidade anterior desapareceu, eu me sentia sinistro e perturbado. Gautsch permaneceu lá, aguardando uma resposta; certamente tinha percebido meu alvoroço, pois me observava atentamente. Ficamos em silêncio.

\section{REFERÊNCIAS BIBLIOGRÁFICAS:}

JÜNGER, E. "Die Staubdämonen, eine Studie zu Alfred Kubins Werk". In: E. Ernst Jünger Werke. Stuttgart: Ernst Klett Verlag, s. data. Band 8 Essays IV, fls. 491-498

KANDINSKI, W. Do Espiritual na Arte, e na pintura em particular. Tradução Álvaro Cabral e Antonio de Pádua Danesi. São Paulo: Martins Fontes, 1996.

KUBIN, A. Die andere Seite. Reinbek bei Hamburg: Rowohlt, 2001. Metzler-Autorenlexikon. Stuttgart: Metzler, 1986.

METZLER, J. B. Metzler-Autorenlexikon. Stuttgart: Metzler, 1986.

RIBEIRO, N. S. Oswaldo Goeldi - um auto-retrato. Tradução das cartas alemão/português de Cassiano Durand, Hans Rudolf Dietiker, Ingeborg Angele, Maria Kikoler e Vera Lins. Rio de Janeiro: CCBB, 1995. 
Estalos nas vigas - literatura e desenhos de Alfred Kubin | 49

Recebido em: 02 de setembro de 2016. Aceito em: 10 de dezembro de 2016. 